\title{
Special Issue: Genomic Analyses of Avian Evolution
}

\author{
Peter Houde \\ Department of Biology, New Mexico State University, Las Cruces, NM 88003, USA; phoude@nmsu.edu
}

Received: 26 September 2019; Accepted: 27 September 2019; Published: 29 September 2019

\begin{abstract}
Genomic Analyses of Avian Evolution" is a "state of the art" showcase of the varied and rapidly evolving fields of inquiry enabled and driven by powerful new methods of genome sequencing and assembly as they are applied to some of the world's most familiar and charismatic organisms-birds. The contributions to this Special Issue are as eclectic as avian genomics itself, but loosely interrelated by common underpinnings of phylogenetic inference, de novo genome assembly of non-model species, and genome organization and content.
\end{abstract}

Keywords: Aves; phylogenomics; genome assembly; non-model species; genome organization

Birds have been the focus of pioneering studies of evolutionary biology for generations, largely because they are abundant, diverse, conspicuous, and charismatic [1]. Ongoing individual and extensively collaborative programs to sequence whole genomes or a variety of pan-genomic markers of all 10,135 described species of living birds further promise to keep birds in the limelight in the near and indefinite future [2,3]. Such comprehensive taxon sampling provides untold opportunities for comparative studies in well documented phenotypic, adaptive, ecological, behavioral, and demographic contexts, while elucidating differing characteristics of evolutionary processes across the genome and among lineages [4,5]. "Genomic Analyses of Avian Evolution" is a timely snapshot of the rapid ontogeny of these diverse endeavors. It features one review and seven original research articles reflecting an eclectic sample of studies loosely interrelated by common themes of phylogenetic inference, de novo genome assembly of non-model species, and genome organization and content.

Avian phylogeny is addressed at a variety of taxonomic levels in these pages. Two papers [6,7] are contributed by leading figures of ongoing phylogenome projects that aspire to resolve the phylogeny of all species of birds, i.e., B10K [2] and The OpenWings Project [3]. Stiller and Zhang [6] provide an overarching review of state of the art methods of sequencing and chromosomal assembly, the B10K Project plan and its current progress (species representing $92 \%$ of all extant families completed), and key findings relating to supraordinal phylogeny and the genomic basis and evolution of specific adaptive traits. The OpenWings Project is racing towards a comprehensive phylogeny of all bird species using a sequence capture approach rather than whole genome sequencing. Kimball et al. [7] present a time-calibrated supertree of 707 species, while providing a detailed account of the methods, nuances, and advantages of the supertree "divide-and-conquer approach for large-scale phylogeny inference."

Two papers resolve phylogeny of extinct species using ancient DNA. Irestedt et al. [8] focus on the genetic diversity and demographics of the Paradise Parrot leading up to its extinction and identify its sister species. In yet another defeat for hypotheses of Gondwana origin of flightless southern endemics [9-11], Boast et al. [12] identify the sister of the enigmatic adzebills as flufftails, and present a novel phylogeographic hypothesis for their ancestor's long distance dispersal to New Zealand via Madagascar.

It has long been acknowledged that different data types afford varying resolution and perspectives on avian phylogeny $[13,14]$. More recently, there is also increasing appreciation for the benefits of multispecies coalescent (MSC) analyses to resolve species trees from incompatible gene trees that result from incomplete lineage sorting ("ILS") in rapid evolutionary radiations. Houde et al. [15] explore 
the characteristics and efficacy of insertion/deletion markers in comparison to nucleotides in a novel application of the MSC application Accurate Species Tree ALgorithm (ASTRAL) [16].

Novel genomes produced for this Special Issue include the Gyrfalcon [17], Paradise Parrot [8], and Hairy-crested Antbird [18], as well as the mitogenomes of the North Island and South Island adzebills, Gray-winged trumpeter, Limpkin, and Red-chested flufftail, and Grey-throated rail [12]. Joseph et al. [17] further resolve genome organization among falcons with new complete chromosome assemblies of Peregrine and Saker falcons, combining whole genome sequencing with fluorescence in situ hybridization (FISH) mapped karyotypic data. Coelho et al. [18] tackle chromosome-level genome organization in the first-published antbird (Thamnophilidae) genome, using an economical linked-read approach instead.

Avian genome organization is also addressed by Kahn et al. [19] in the context of immune system toll-like receptor gene gain and loss in a broad comparison across 79 vertebrates. They implicate rapid evolution and specific radical amino acid substitutions under selection in birds that are likely adaptive responses to recognize and cope with diversified pathogen ligands.

The Editors of Diversity are commended for recognizing the prominent role of bird studies in pioneering vistas of modern genomics. In both the immediate and foreseeable future, Diversity will continue this tradition by featuring seminal research and synthetic reviews in the vibrant and multifaceted fields of avian genomics and evolution, as for example in the upcoming Special Issue "The Origins of Modern Avian Biodiversity." The authors collectively thank Diversity and its Editors for generously providing this platform and subsidizing the Open Access publication of the papers presented in this Special Issue. We are also pleased to have had the opportunity for Open Review, and we support its increasing popularity.

\section{References}

1. Kraus, R.H.S. An Introduction to "Avian Genomics in Ecology and Evolution: From the Lab into the Wild. In Avian Genomics in Ecology and Evolution: From the Lab into the Wild; Kraus, R.H.S., Ed.; Springer International Publishing: Cham, Switzerland, 2019; pp. 1-6.

2. Home|B10K Database. Available online: https://b10k.genomics.cn/ (accessed on 21 September 2019).

3. The OpenWings Project. Available online: https://www.openwings.org/ (accessed on 21 September 2019).

4. Jarvis, E.D.; Mirarab, S.; Aberer, A.J.; Li, B.; Houde, P.; Li, C.; Ho, S.Y.W.; Faircloth, B.C.; Nabholz, B.; Howard, J.T.; et al. Whole-genome analyses resolve early branches in the tree of life of modern birds. Science 2014, 346, 1320-1331. [CrossRef] [PubMed]

5. Zhang, G.; Li, C.; Li, Q.; Li, B.; Larkin, D.M.; Lee, C.; Storz, J.F.; Antunes, A.; Greenwold, M.J.; Meredith, R.W.; et al. Comparative genomics reveals insights into avian genome evolution and adaptation. Science 2014, 346, 1311-1320. [CrossRef] [PubMed]

6. Stiller, J.; Zhang, G. Comparative phylogenomics, a stepping stone for bird biodiversity studies. Diversity (Basel) 2019, 11, 115. [CrossRef]

7. Kimball, R.T.; Oliveros, C.H.; Wang, N.; White, N.D.; Barker, F.K.; Field, D.J.; Ksepka, D.T.; Chesser, R.T.; Moyle, R.G.; Braun, M.J.; et al. A phylogenomic supertree of birds. Diversity (Basel) 2019, 11, 109. [CrossRef]

8. Irestedt, M.; Ericson, P.G.P.; Johansson, U.S.; Oliver, P.; Joseph, L.; Blom, M.P.K. No Signs of Genetic Erosion in a 19th Century Genome of the Extinct Paradise Parrot (Psephotellus pulcherrimus). Diversity (Basel) 2019, 11, 58. [CrossRef]

9. Harshman, J.; Braun, E.L.; Braun, M.J.; Huddleston, C.J.; Bowie, R.C.K.; Chojnowski, J.L.; Hackett, S.J.; Han, K.-L.; Kimball, R.T.; Marks, B.D.; et al. Phylogenetic evidence for multiple losses of flight in ratite birds. Proc. Natl. Acad. Sci. USA 2008, 105, 13462-13467. [CrossRef] [PubMed]

10. Phillips, M.J.; Gibb, G.C.; Crimp, E.A.; Penny, D. Tinamous and moa flock together: Mitochondrial genome sequence analysis reveals independent losses of flight among ratites. Syst. Biol. 2010, 59, 90-107. [CrossRef]

11. Mitchell, K.J.; Llamas, B.; Soubrier, J.; Rawlence, N.J.; Worthy, T.H.; Wood, J.; Lee, M.S.Y.; Cooper, A. Ancient DNA reveals elephant birds and kiwi are sister taxa and clarifies ratite bird evolution. Science 2014, 344, 898-900. [CrossRef] 
12. Boast, A.; Chapman, B.; Herrera, M.; Worthy, T.; Scofield, R.; Tennyson, A.; Houde, P.; Bunce, M.; Cooper, A.; Mitchell, K. Mitochondrial Genomes from New Zealand's Extinct Adzebills (Aves: Aptornithidae: Aptornis) Support a Sister-Taxon Relationship with the Afro-Madagascan Sarothruridae. Diversity (Basel) 2019, 11, 24. [CrossRef]

13. Wink, M. A historical perspective of avian genomics. In Avian Genomics in Ecology and Evolution: From the Lab into the Wild; Kraus, R.H.S., Ed.; Springer International Publishing: Cham, Switzerland, 2019; pp. 7-19.

14. Braun, E.L.; Cracraft, J.; Houde, P. Resolving the avian tree of life from top to bottom: The promise and potential boundaries of the phylogenomic era. In Avian Genomics in Ecology and Evolution-from the Lab into the Wild; Kraus, R.H.S., Ed.; Springer: Cham, Switzerland, 2019.

15. Houde, P.; Braun, E.L.; Narula, N.; Minjares, U.; Mirarab, S. Phylogenetic signal of indels and the neoavian radiation. Diversity (Basel) 2019, 11, 108. [CrossRef]

16. Sayyari, E.; Mirarab, S. Fast Coalescent-Based Computation of Local Branch Support from Quartet Frequencies. Mol. Biol. Evol. 2016, 33, 1654-1668. [CrossRef] [PubMed]

17. Joseph, S.; O'Connor, R.; Al Mutery, A.; Watson, M.; Larkin, D.; Griffin, D. Chromosome Level Genome Assembly and Comparative Genomics between Three Falcon Species Reveals an Unusual Pattern of Genome Organisation. Diversity (Basel) 2018, 10, 113. [CrossRef]

18. Coelho, L.; Musher, L.; Cracraft, J. A Multireference-Based Whole Genome Assembly for the Obligate Ant-Following Antbird, Rhegmatorhina melanosticta (Thamnophilidae). Diversity (Basel) 2019, 11, 144. [CrossRef]

19. Khan, I.; Maldonado, E.; Silva, L.; Almeida, D.; Johnson, W.E.; O’Brien, S.J.; Zhang, G.; Jarvis, E.D.; Gilbert, M.T.P.; Antunes, A. The vertebrate TLR supergene family evolved dynamically by gene gain/loss and positive selection revealing a host-pathogen arms race in birds. Diversity (Basel) 2019, 11, 131. [CrossRef]

(C) 2019 by the author. Licensee MDPI, Basel, Switzerland. This article is an open access article distributed under the terms and conditions of the Creative Commons Attribution (CC BY) license (http://creativecommons.org/licenses/by/4.0/). 